\title{
Granular ferric hydroxide adsorbent for phosphate removal: demonstration preparation and field study
}

\author{
Bei Zhao, Yu Zhang, Xiaomin Dou, Hongying Yuan and Min Yang
}

\begin{abstract}
$\overline{\text { ABSTRACT }}$
Ferric hydroxide (FHO), which has high phosphate adsorption capacity, was prepared by precipitation at industrial scale and then fabricated via the drum granulation method with crosslinked poly(vinyl alcohol) as the binder. The optimum binder/FHO powder ratio was 0.6 for producing a granular adsorbent with a high phosphate adsorption capacity and stability. The Langmuir maximum adsorption capacities of powder and granular FHOs were $74.07 \mathrm{mg} \mathrm{g}^{-1}$ and $56.18 \mathrm{mg} \mathrm{g}^{-1}$ at $\mathrm{pH} 7.0 \pm 0.2$, respectively, which were higher than those of other reported phosphate adsorbents under neutral or acidic conditions. Phosphate-loaded granular FHO could be regenerated by $\mathrm{NaOH}$ solution. Columns containing the granular FHO were used for phosphate removal from ozonated secondary effluents of a municipal wastewater treatment plant at space velocity (SV) of 2 and $5 \mathrm{~h}^{-1}$. During more than 2 months' operation, the average removal percentage of $\mathrm{PO}_{4}^{3-}$ was more than $90 \%$ and the turbidity and concentration of $\mathrm{COD}_{\mathrm{Mn}}$ in the effluents were lower than in the influents. In addition, energy dispersive $\mathrm{X}$-ray results suggested that active sites inside the granular $\mathrm{FHO}$ were available for phosphate removal. The results demonstrated that granular FHO can be applied as an assist technology for phosphate removal from secondary effluents.

Key words | adsorption, field test, granulation, phosphate removal, secondary effluents
\end{abstract}

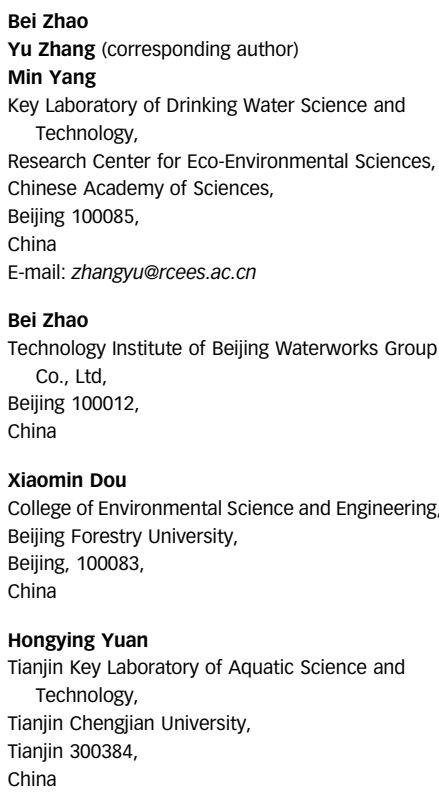

\section{INTRODUCTION}

Excess discharge of phosphorus into surface waters often causes eutrophication, which affects the water quality through consumption of dissolved oxygen and destroys aquatic life (Correll I998). Biological processes and chemical precipitation have been mainly used for phosphate removal from municipal wastewater (Morse et al. 1998; Clauson-Kaas et al. 2004). However, these techniques are both associated with disadvantages such as operational difficulties, sludge production, phosphate recycling and, especially, incomplete removal (Morse et al. 1998; Blaney et al. 2007). Additionally, the presence of low concentrations of phosphate (even less than $1 \mathrm{mg} \mathrm{l}^{-1}$ ) in the treated municipal wastewater may cause eutrophication if the streams discharge into lakes or reservoirs (Zhao \& Sengupta 1998; Peleka \& Deliyanni 2009). Therefore, adsorption has been considered as an assist technology with efficient and cost-benefit performance for steady phosphate removal from water (Wei et al. 2008), particularly for low phosphate concentrations (Tian et al. 2009). Many types of phosphate adsorbents have been investigated, including raw or modified low-cost materials (Tian et al. 2009; Boyer et al. 20п) and metal oxides (Zeng et al. 2004; Pan et al. 2009). Among these, ferric based oxides/hydroxides have proved to exhibit excellent selective adsorption of phosphate (Chitrakar et al. 2006). Therefore, for convenience of operation in fixed-bed units and reuse, it is important to fabricate powdered ferric-based oxides/hydroxides into granular adsorbents.

The easily realized methods for the preparation of granular adsorbents are coating and loading, which involve coating or impregnating active components onto a carrier (Mezenner \& Bensmaili 2009; Tian et al. 2009; Aryal \& LiakopoulouKyriakides 20II). However, these adsorbents suffer from low adsorption capacity due to limited amounts of active components, and lack the mechanical strength and durability for prolonged operation in fixed-bed units (Chen et al. 20II). Among several granulation technologies reported (Salman et al. 2007; Dou et al. 2013), the drum granulation method is considered to be the simplest continuous mechanism and is 
widely used in the granulation of fertilizers. It can fabricate higher porosity granules with larger powder loadings from powdered materials without a carrier core. Recently, the drum granulation method has been reported to be successfully applied in the preparation of granular schwertmannite for arsenate adsorption (Dou et al. 20I3). To fabricate a durable adsorbent for operation in fixed-bed units by drum granulation, the binder is very important in order to make individual particles coalesce and to provide cohesive forces at particle contact points, so that the granules are able to tolerate stress (Walker 2007). According to previous research, poly (vinyl alcohol) (PVA) had been successfully used as a binder for granulation of a iron-aluminum-cerium ( $\mathrm{Fe}-\mathrm{Al}-$ Ce) trimetal hydroxide adsorbent for fluoride (F) removal (Zhao et al. 2012). Therefore, it is worthwhile to investigate the fabrication of granular ferric based adsorbents for phosphate removal using the above method. Meanwhile, to promote the application of a granular adsorbent, it is also important to realize demonstration of the preparation at industrial scale and conduct field tests for treatment of secondary effluents.

In the present study, a ferric hydroxide (FHO) powder was prepared at industrial-scale in a factory and then fabricated by drum granulation using cross-linked PVA as the binder to obtain a granular FHO adsorbent. The binder/ FHO powder ratio was optimized to prepare a suitable granular FHO for phosphate removal. The adsorption capacity of the granular FHO was investigated through batch tests and compared with other phosphate adsorbents. The adsorption performance of the granular FHO for secondary effluents from a municipal wastewater treatment plant was evaluated by field column testing for more than 2 months, showing an attractive application potential.

\section{MATERIALS AND METHODS}

\section{Materials}

The technical grade ferric sulfate and $\mathrm{NaOH}$ were supplied by the Xinbang Chemical Company (Shandong, China). The $\mathrm{KH}_{2} \mathrm{PO}_{4}$ (guaranteed reagent, GR) and other analytical reagent $(\mathrm{AR})$ grade chemicals were all obtained from the China National Medicines Company (Beijing, China).

\section{Adsorbent preparation and its granulation}

The FHO powder was prepared by precipitation as described in a previous publication (Schwertmann \& Cornell 2000), with modifications, in a factory at Dongying City, Shandong Province China. Specifically, $3 \mathrm{~m}^{3}$ of a ferric sulfate solution with $0.10 \mathrm{~mol} \mathrm{l}^{-1} \mathrm{Fe}$ and $0.73 \mathrm{~m}^{3} 6 \mathrm{~mol} \mathrm{l}^{-1}$ of a $\mathrm{NaOH}$ solution were mixed under continuous stirring at $100 \mathrm{rpm}$. The $\mathrm{NaOH}$ solution was added gradually, and the relationship between the volume of $\mathrm{NaOH}$ solution and the $\mathrm{pH}$ of the reaction system during the preparation process are shown in Figure S1 (see Supplementary Information, available in the online version of this paper). After aging at room temperature for $12 \mathrm{~h}$, the precipitate was washed with tap water until the electrical conductivity of the supernatant was below 4.0 $\mathrm{mS} \mathrm{cm}{ }^{-2}$, and then sprayed at $271{ }^{\circ} \mathrm{C}$ to a fine powder. The preparation steps and illustrative photographs are shown in Figure S2 (available in the online version of this paper).

The powder was fabricated with the same binder used in our previous study (Zhao et al. 2012) via the drum granulation method on an oscillating granulator. After drying at $65^{\circ} \mathrm{C}$, the granules were sieved to give a particle size range of $1.4-1.7 \mathrm{~mm}$. A schematic diagram of the preparation process is illustrated in Figure 1(a).

\section{Characterization}

The specific surface areas and pore size distribution of the powder and granular FHO adsorbents were determined using a Specific Surface Area Analyzer (TriStar II 3020; Micromeritics Instrument Corporation, USA). The X-ray diffraction pattern of the FHO powder was recorded on an X-ray Diffractometer (X'Pert Pro Mp, Panalytical, The Netherlands). The selective dissolution of amorphous iron oxides from FHO was conducted using a previously reported method (Chao \& Zhou 1983). The surface morphology of the powder and granular FHOs and distributions of phosphorus on the transverse sections of the granular FHO granules after field column testing were revealed by an Energy Dispersive X-ray (EDX) Analytical Spectrometer (EDAX Inc., USA) connected to a Scanning Electron Microscope (SEM, S-3000N; HITACHI, Japan). The stability of granular FHO in water was evaluated by a previously reported method (Zhao et al. 20I2).

\section{Phosphate adsorption experiments}

For adsorption isotherm experiments, a stock solution containing $500 \mathrm{mg} \mathrm{l}^{-1}$ phosphate ion $\left(\mathrm{PO}_{4}^{3-}\right)$ was prepared by dissolving $0.7165 \mathrm{~g}$ of $\mathrm{KH}_{2} \mathrm{PO}_{4}$ in 11 deionized water. Working solutions (initial $\mathrm{PO}_{4}^{3-}$ concentrations, 5-200 $\mathrm{mg} \mathrm{l}^{-1}$ ) were prepared by diluting the stock solution with deionized water. The $0.20 \mathrm{~g}$ samples of granular adsorbent and $100 \mathrm{~m}$ 

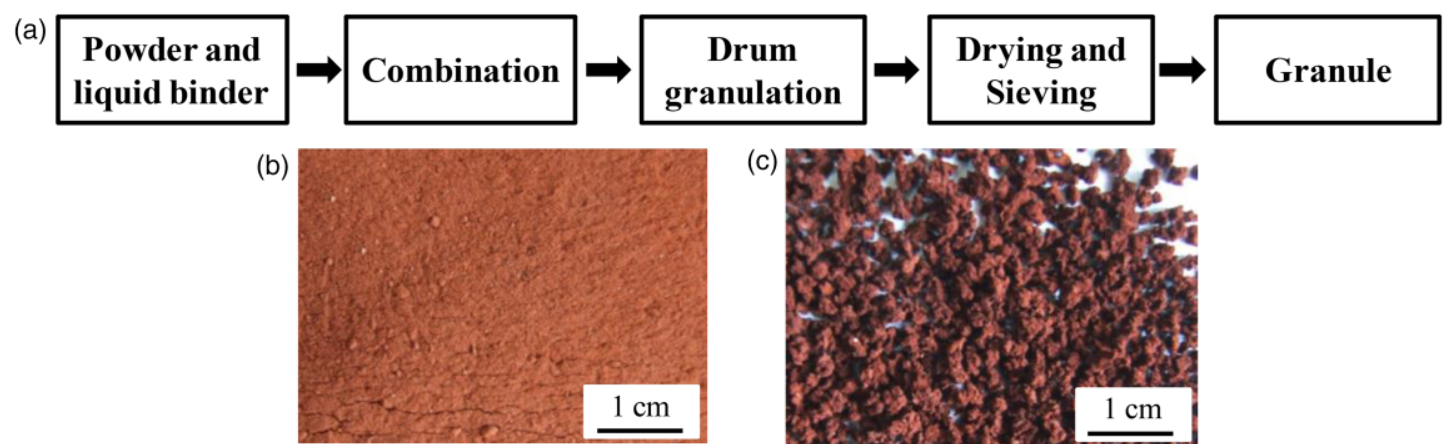

(d)

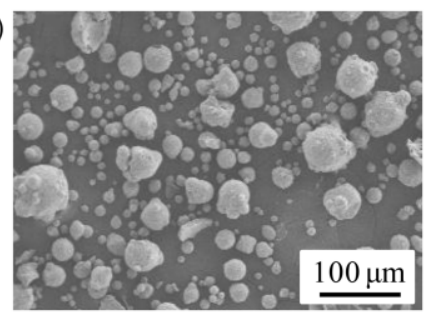

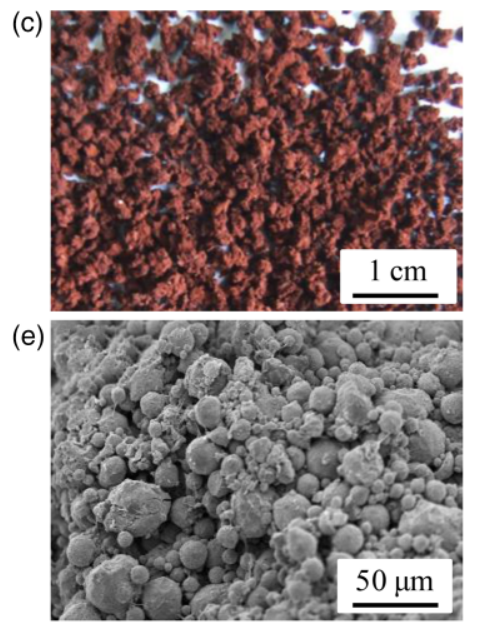

(c)

(e)

Figure 1 | Schematic of the preparation process steps and images of powder and granular FHOs (at binder/powder ratio 0.6) ((a) preparation process steps of the granular FHO; (b) image of the FHO powder; (c) image of the granular FHO; (d) SEM image of the FHO powder; (e) SEM image of the granular FHOS).

working solutions were added to $250 \mathrm{~mL}$ conical flasks and shaken at $130 \mathrm{rpm}, 25^{\circ} \mathrm{C}$ for $24 \mathrm{~h}$.

The test solution $\mathrm{pH}$ was adjusted to $\mathrm{pH} 7.0 \pm 0.2$ with 0.1 $\mathrm{mol} \mathrm{l}^{-1} \mathrm{HCl}$ or $0.1 \mathrm{~mol}^{-1} \mathrm{NaOH}$. The samples were then filtered using $0.45 \mu \mathrm{m}$ membrane filters. The residual $\mathrm{PO}_{4}^{3-}$ concentrations were determined at $700 \mathrm{~nm}$ with an Ultraviolet/visible Spectrophotometer (U-3010, Hitachi, Japan) by the molybdenum-blue ascorbic acid method of a blue soluble complex formed between phosphate, ammonium molybdate $\left(\left(\mathrm{NH}_{4}\right)_{6} \mathrm{Mo}_{7} \mathrm{O}_{24} \cdot 4 \mathrm{H}_{2} \mathrm{O}\right)$ and antimony potassium tartrate $\left(\mathrm{K}(\mathrm{SbO}) \mathrm{C}_{4} \mathrm{H}_{4} \mathrm{O}_{6} \cdot 1 / 2 \mathrm{H}_{2} \mathrm{O}\right)$ in the presence of ascorbic acid as reducing agent. The adsorption experiments were carried out in triplicate and average values were reported.

The amount of adsorbed $\mathrm{PO}_{4}^{3-}\left(\mathrm{Q}_{\mathrm{e}}, \mathrm{mg} \mathrm{g}^{-1}\right)$ was determined as follows:

$Q_{e}=\left(C_{0}-C_{e}\right) \times V / m$

where $C_{0}$ and $C_{e}$ are the initial and final $\mathrm{PO}_{4}^{3-}$ concentrations $\left(\mathrm{mg} \mathrm{l}^{-1}\right)$, respectively, $V$ is the volume of test solution (l), and $m$ is the mass of the granular adsorbent (g).

\section{Regeneration experiments}

Three gram samples of granular FHO were loaded in $2,000 \mathrm{ml}$ conical flasks containing $1,500 \mathrm{ml}$ solutions with $20 \mathrm{mg} \mathrm{l}^{-1} \mathrm{PO}_{4}^{3-}$, and shaken at $130 \mathrm{rpm}, 25^{\circ} \mathrm{C}$ for $48 \mathrm{~h}$. The granular FHO was collected and washed using deionized water and dried at $65^{\circ} \mathrm{C}$. The recovered granular FHOs at $5 \mathrm{~g} \mathrm{l}^{-1}$ were soaked in $20 \mathrm{ml} \mathrm{NaOH}$ solutions of different concentration for $4 \mathrm{~h}$. The $\mathrm{PO}_{4}^{3-}$ concentrations in the adsorption and desorption solutions were determined by the same method as described above. After desorption, the granular FHO was activated using $20 \mathrm{ml}$ dilute sulfuric acid at $\mathrm{pH} 4.0$ for $1 \mathrm{~h}$ followed by washing with deionized water. After regeneration, the adsorption capacity of the granular FHOs was tested at the same initial $\mathrm{PO}_{4}^{3-}$ concentration and granule dosage as for the adsorption step. The regeneration experiments were carried out in triplicate and average values were reported.

The desorption efficiency and regeneration efficiency were determined as follows:

$$
\begin{aligned}
& \text { Desorption efficiency }=\text { the amount of } \mathrm{PO}_{4}^{3-} \text { desorbed } / \\
& \text { the amount of } \mathrm{PO}_{4}^{3-} \text { adsorbed }(\text { fresh }) \times 100 \%
\end{aligned}
$$

$$
\begin{aligned}
& \text { Regeneration efficiency }=\text { the amount of } \mathrm{PO}_{4}^{3-} \\
& \text { adsorbed(reuse)/theamount of } \mathrm{PO}_{4}^{3-} \text { adsorbed }(\text { fresh }) \times 100 \%
\end{aligned}
$$

\section{Field column test}

Perspex columns with an inner diameter of $5 \mathrm{~cm}$ and height of $60 \mathrm{~cm}$ were used to evaluate the adsorption performance of granular FHO in treating secondary effluents 
which discharge into lakes or other natural water bodies. The ozonated secondary effluents from a municipal wastewater treatment plant were subjected to further treatment by ozonation and biological activated carbon in a pilotscale system, and then fed into the columns. The water quality of the influents and effluents of the columns were sampled at regular time intervals for water quality analysis during the more than 2 months' operation. For the influents, the $\mathrm{pH}$ was $7.46-8.42$ (average: 8.03 ), the turbidity was $0.20-5.42$ (average: 0.70 ), the concentration of dissolved organic carbon (DOC) was 5.52-12.01 (average: $8.23 \mathrm{mg} \mathrm{l}^{-1}$ ), the concentration of permanganate index $\left(\mathrm{COD}_{\mathrm{Mn}}\right)$ was $4.37-8.46 \mathrm{mg} \mathrm{l}^{-1}$ (average: $5.37 \mathrm{mg}$ $\left.1^{-1}\right)$, and $\mathrm{PO}_{4}^{3-}$ concentration was $0.21-1.40 \mathrm{mg} \mathrm{l}^{-1}$ (average: $0.63 \mathrm{mg} \mathrm{l}^{-1}$ ), respectively. The adsorbent volume was $600 \mathrm{ml}$, and the space velocities (SV, the volume of treatment water per hour/the volume of granular FHO in the perspex column) were 2 and $5 \mathrm{~h}^{-1}$. A picture of the columns used in the field test is shown in Figure 2(b).

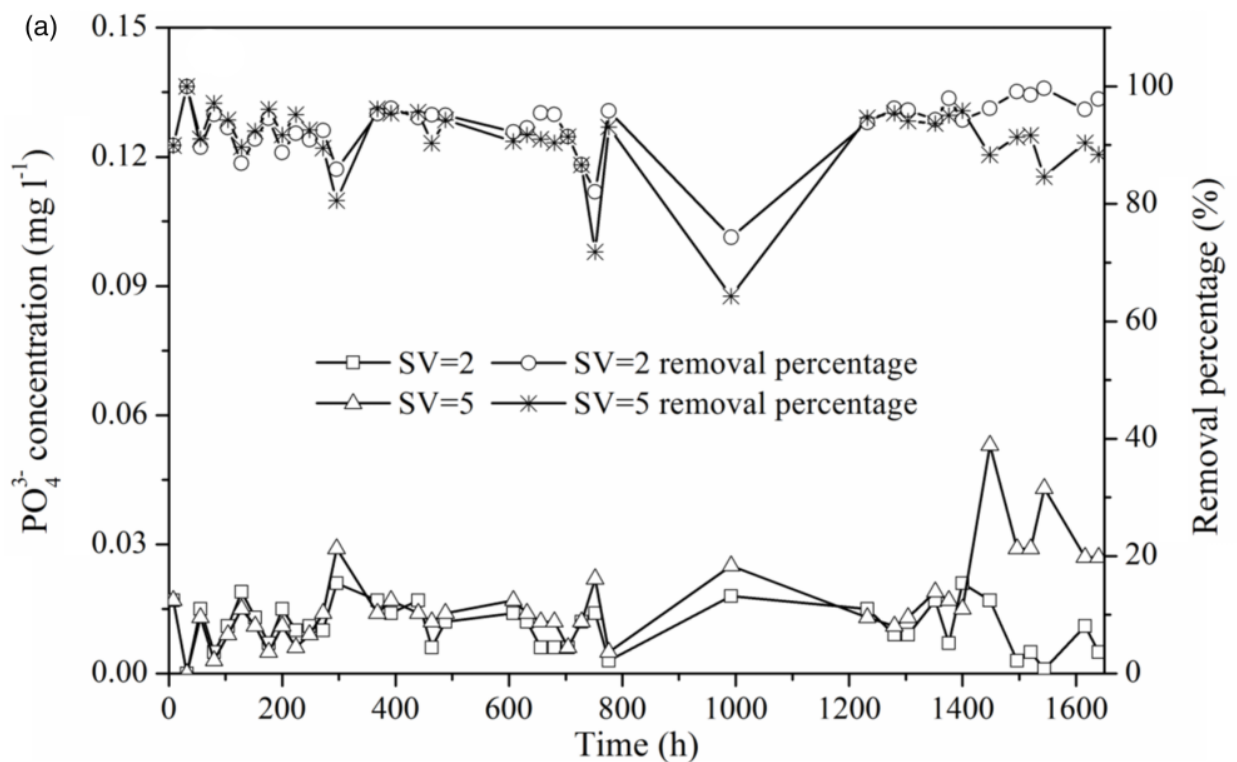

(b)

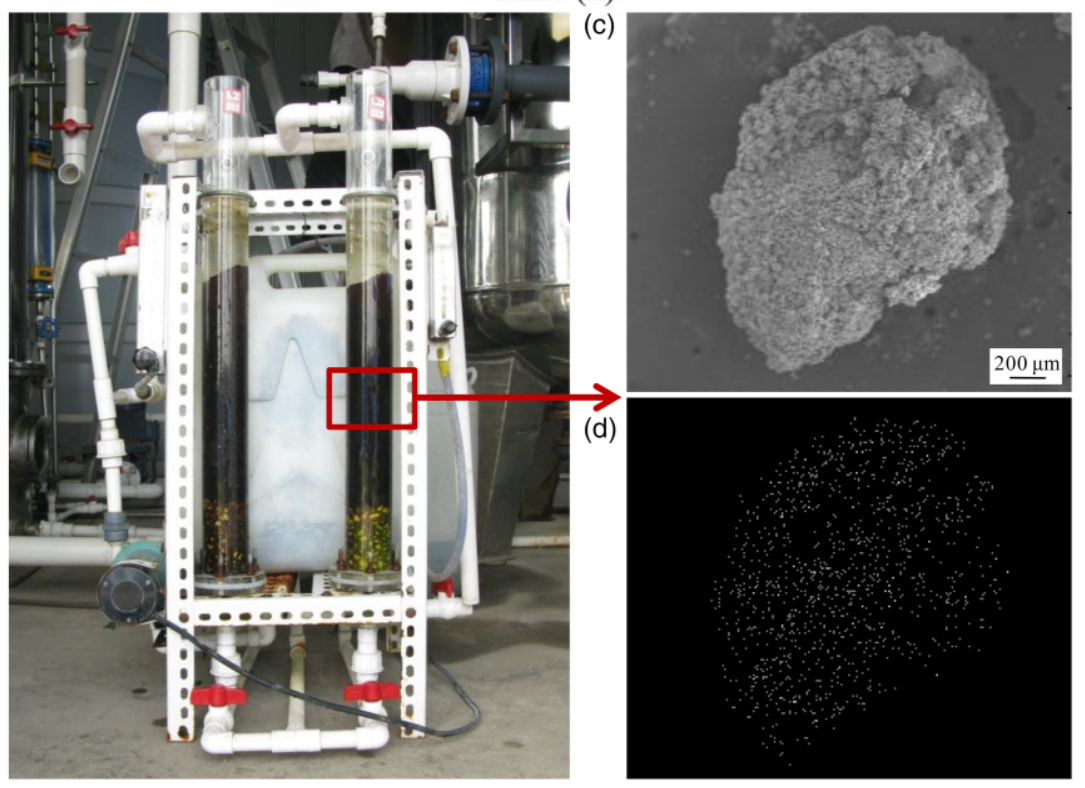

Figure 2 | Field column test ((a) $\mathrm{PO}_{4}^{3-}$ removal performance by the granular FHO; (b) the columns used in the field column test; (c) SEM pattern of a granular FHO after used in the field column test; (d) mapping mode image of phosphorus element distribution along the cross-section of the granular FHO (dot-P)). 


\section{RESULTS AND DISCUSSION}

\section{Characterization of FHO powder}

The FHO powder prepared by precipitation and spray drying in a factory was composed of loose and spherical particles, as shown in Figure 1(b) and (d). The BrunauerEmmett-Teller (BET) specific surface area of the FHO powder was $220.6 \mathrm{~m}^{2} \mathrm{~g}^{-1}$ and the pore volume was $0.33 \mathrm{~cm}^{3} \mathrm{~g}^{-1}$. The X-ray diffraction (XRD) pattern (Figure S3, available in the online version of this paper) illustrated that the FHO powder had an amorphous structure with a small amount of schwertmannite (according to PDF 47-1775). The results of selective dissolution confirmed that the FHO powder was composed of more than $90.7 \%$ amorphous ferric hydroxide. In summary, the FHO was a powder with large specific surface area, abundant pores and amorphous structure, which are beneficial for achieving high adsorption capacity (Zhang et al. 2005).

\section{Granulation of FHO powder}

Because the FHO was a loose powder, a binder was essential to make individual particles coalesce and fabricate a durable granular adsorbent (Walker 2007). The binder, which was the same as that used in a previous study, (Zhao et al. 20I2) was introduced, and the effects of the binder/powder ratio on the granulation process were evaluated. The properties and phosphate adsorption capacity of granular FHOs with different ratios are shown in Table S1 (available in the online version of this paper). When the binder/powder ratio was 0.3 or less, the mixture was still loose and could not be made into granules via drum granulation. When the binder/powder ratio rose to 0.6 , the wet mass was mixed well and could be fabricated into granules (Figure S4(c)) (Figure S4 is available in the online version of this paper). After drying, these granules showed good stability $(91.0 \%)$ owing to the micro-particles of the FHO being combined together by the binder (Figure S4(e)). When the binder/ powder ratio continued to rise up to 1.0 , the stability of granular FHO increased slightly to $97.2 \%$, while the BET specific surface areas and adsorption capacity were basically the same. However, the wet mass of the binder/powder ratio 1.0 was too sticky to pass easily through the machine, which decreased the production yield of the granular FHO significantly, and the cleaning of the machine was difficult. Therefore, the binder/powder ratio of 0.6 was selected as the optimum ratio for subsequent experiments.

\section{Phosphate removal performance of optimized granular FHO}

The equilibrium $\mathrm{PO}_{4}^{3-}$ adsorption isotherms and Langmuir maximum adsorption capacities for powder and granular FHO are shown in Figure S4 and Table 1. As shown in Table 1, the adsorption capacity of FHO powder was $74.07 \mathrm{mg} \mathrm{g}^{-1}$, which was higher than that of some commercial powder adsorbents (hydrotalcite, $60 \mathrm{mg} \mathrm{g}^{-1}$; aluminium oxide S, $34.57 \mathrm{mg} \mathrm{g}^{-1}$ ) (Peleka \& Deliyanni 2009). After granulation, the adsorption capacity and BET surface area of granular FHO were $56.18 \mathrm{mg} \mathrm{g}^{-1}$ and $177.0 \mathrm{~m}^{2} \mathrm{~g}^{-1}$, which were $75.8 \%$ and $80.2 \%$ those of powder $\mathrm{FHO}$, respectively.

Table 1 also lists the adsorption capacities of six granular metal oxide adsorbents prepared by impregnation, loading or extrusion in other studies. The adsorption capacities of three ferric oxide/hydroxide adsorbents prepared by impregnation or loading were 7.04, 10.60 and $50 \mathrm{mg} \mathrm{g}^{-1}$ at neutral pH (Blaney et al. 2007; Mezenner \& Bensmaili 2009; Yue et al. 20I0). The adsorption capacities of the other three adsorbents tested under acidic conditions were also below $50 \mathrm{mg} \mathrm{g}^{-1}$ (Tian et al. 2009; Yue et al. 20Io; Aryal \& Liakopoulou-Kyriakides 20II). Among all of the above adsorbents, the granular FHO showed the highest adsorption capacity at neutral $\mathrm{pH}$. This may be attributed to its large powder loading (more than 99\% per dry adsorbent) and high specific surface area $\left(177.0 \mathrm{~m}^{2} \mathrm{~g}^{-1}\right)$. Therefore, the relatively high phosphate adsorption capacity of granular $\mathrm{FHO}$ at neutral $\mathrm{pH}$ is a major advantage.

\section{Regeneration and reuse}

Regeneration and reuse ability is as important as high adsorption capability for an advanced adsorbent, and can significantly reduce running cost. Regeneration agents such as $\mathrm{NaOH}$ have been used for phosphate-loaded adsorbents composed of metals or metal oxides such as lanthanum/ aluminum pillared montmorillonite (Tian et al. 2009), polymer-based nanosized hydrated ferric oxides (Pan et al. 2009), and Fe(III)-treated Staphylococus xylosus biomass (Aryal \& Liakopoulou-Kyriakides 20II). According to the adsorption mechanism, $\mathrm{HPO}_{4}^{2-}$ exchanges with surface $\mathrm{OH}$ groups, forming an inner sphere complex (Chitrakar et al. 2006). So, in the present study, the phosphate-loaded granular FHOs were regenerated by $\mathrm{NaOH}$ solutions of different concentrations. As shown in Figure S5 (available in the online version of this paper), the desorption efficiency increased from $75.2 \%$ to $85.7 \%$ with the increase of $\mathrm{NaOH}$ 


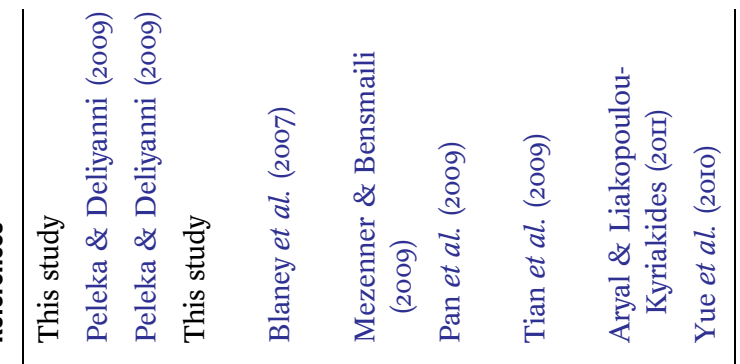

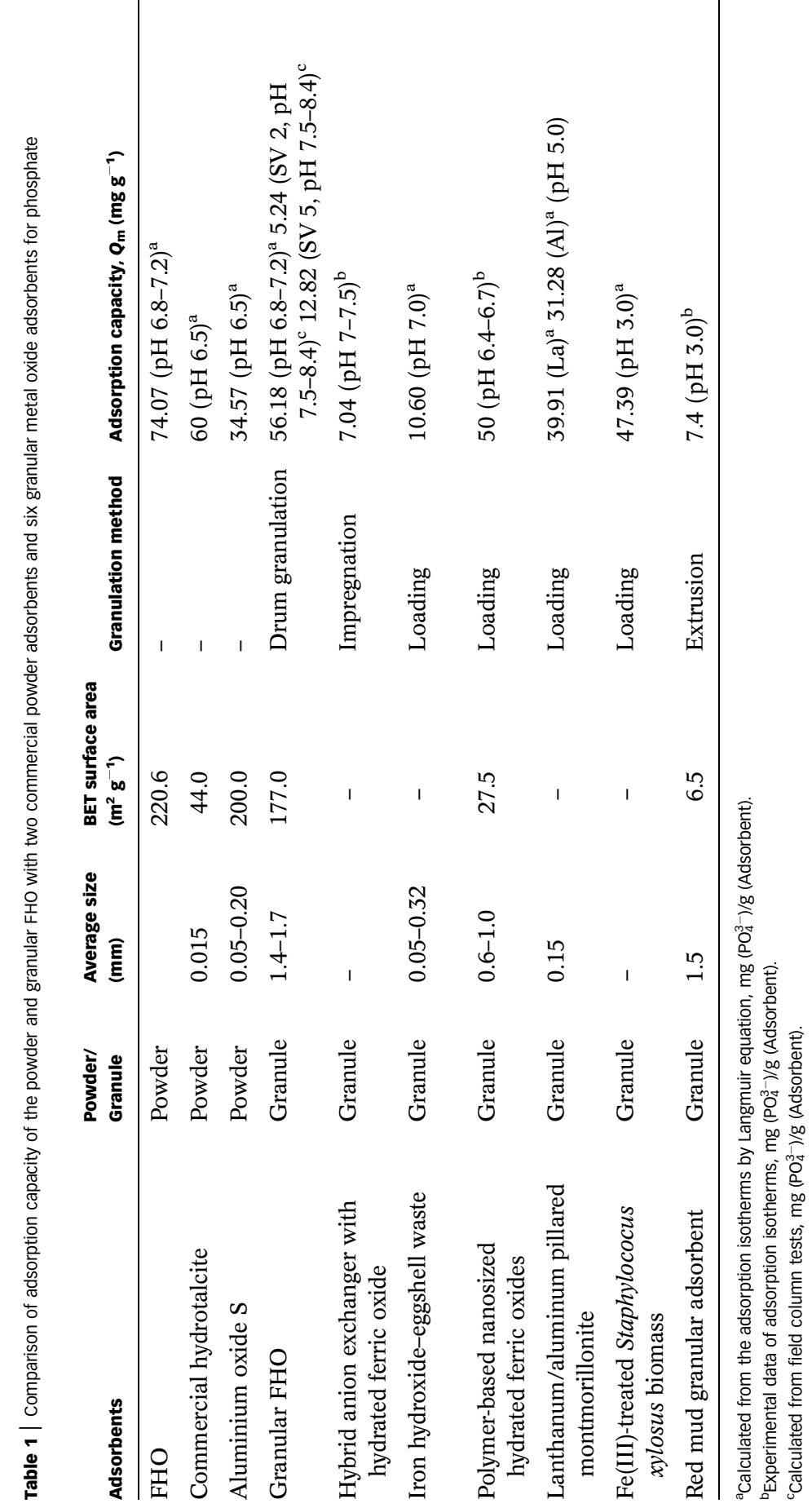


concentration from 0.5 to $2 \mathrm{~mol}^{-1}$. Further increase in $\mathrm{NaOH}$ concentration (up to $5 \mathrm{~mol}^{-1}$ ) did not significantly enhance the desorption efficiency of phosphate. Based on the desorption efficiency and the dosage of $\mathrm{NaOH}$, the granular FHO regenerated by $2 \mathrm{~mol}^{-1} \mathrm{NaOH}$ solution was selected, and 94.8\% regeneration efficiency was achieved compared with the fresh sample. On the other hand, the $\mathrm{PO}_{4}^{3-}$ concentration in the used $2 \mathrm{~mol} \mathrm{l}^{-1} \mathrm{NaOH}$ solution was $44.80 \mathrm{mg}^{-1}$ (in the form of inorganic phosphate). And it may be possible to employ the regeneration solution in $\mathrm{PO}_{4}^{3-}$ recovery as hydroxyapatite (HAP) by calcite-seeded crystallization (Plant \& House 2002). This suggested that the phosphate loaded on the granular FHO can be easily desorbed using a $2 \mathrm{~mol} \mathrm{l}^{-1} \mathrm{NaOH}$ solution, and the material has good potential for use as an adsorbent for phosphate removal.

\section{Field column test}

Although the granular FHO showed efficiency for phosphate adsorption from synthetic water in batch tests, it is also necessary to evaluate its application potential for treatment of secondary effluents in field column tests. Therefore, the adsorption performance of granular FHO for treating actual ozonated secondary effluents from a municipal wastewater treatment plant was evaluated. The secondary effluents were subjected to treatment by ozonation and biologically activated carbon in a pilot-scale system, and then fed into columns at SV $2 \mathrm{~h}^{-1}$ and $5 \mathrm{~h}^{-1}$, respectively. During more than 2 months' operation, the column system kept running steadily without blocking, which exhibited high mechanical strength and durability of the granular FHO used in fixed-bed units. The removal performance of $\mathrm{PO}_{4}^{3-}$ by granular $\mathrm{FHO}$ from the secondary effluents are shown in Figure 2(a) and Table S2 (available in the online version of this paper). After 3,280 bed volumes (BV) and 8,200 BV water treatment, the accumulated adsorption capacities were $5.24 \mathrm{mg} \mathrm{g}^{-1}$ and $12.82 \mathrm{mg} \mathrm{g}^{-1}$ for SV 2 and SV 5, while the average removal percentages of $\mathrm{PO}_{4}^{3-}$ were $93.2 \%$ and $91.0 \%$, respectively. Due to the low influent $\mathrm{PO}_{4}^{3-}$ concentration $(0.21-1.40 \mathrm{mg}$ $\mathrm{1}^{-1}$ ) and limited operation time of the field column tests, the $\mathrm{PO}_{4}^{3-}$ adsorption capacity in the field column tests was lower than the Langmuir maximum adsorption capacities in batch tests. However, the results indicated that the high concentration of competing ions in secondary effluents had no influence on selective adsorption of granular FHO for low concentrations of phosphate. At the end of more than 2 months' operation, the concentrations of $\mathrm{PO}_{4}^{3-}$ in the effluents were still below $0.06 \mathrm{mg} \mathrm{l}^{-1}$ for both operation velocities, which suggested that the adsorption capacity of granular FHOs was not exhausted and the adsorbent could continue to be used. Besides the effective removal of phosphate, the turbidity and concentration of DOC and COD $_{M n}$ in the effluents were also 46, 21 and 16\% lower than in the influents, indicating that the adsorbent not only had durability for operation in columns, but also could remove other contaminants. Thus, the granular FHO has excellent selective capacity and application potential for phosphate removal from secondary effluents.

The SEM image of a FHO granule taken from the column after more than 2 months' operation is shown in Figure 2(c). It is clearly shown that the granule had high porosity and an abundant pore structure with small anomalous particles. To determine whether the phosphate ions could diffuse into the granule and if the inner surface was available for the adsorption of phosphate in the field column test, the phosphorus element distribution inside the granular FHOs was investigated. SEM-EDX in mapping mode can confirm the distribution of the analyzed element on an adsorbent surface and has been employed successfully for the direct detection of distribution maps of $\mathrm{As}, \mathrm{F}$ or $\mathrm{Cu}$ in granular adsorbents (Lai et al. 2000; Zhang et al. 20Io; Zhao et al. 20I2). Figure 2(d) illustrates the phosphorus distribution along the cross-section of the granular FHO after operation in the field column test. The phosphorus is represented as bright points, and can be seen to be spread over the crosssection of the granular FHO, suggesting that nearly all active sites on the inner surface of the granular FHO were available for the adsorption of phosphate.

\section{CONCLUSIONS}

An FHO powder was prepared at industrial-scale and successfully fabricated into granules by drum granulation using cross-linked PVA as the binder. The optimum granular FHO granules were fabricated at the binder/FHO powder ratio 0.6 and exhibited a higher adsorption capacity compared to other phosphate adsorbents under neutral or acidic conditions. The phosphate-loaded granular FHO could be regenerated by $2 \mathrm{moll}^{-1} \mathrm{NaOH}$ solution to achieve $94.8 \%$ regeneration efficiency. In a field column test for treatment of secondary effluents, the average removal percentage of $\mathrm{PO}_{4}^{3-}$ after more than 2 months was more than $90 \%$, and almost all of the active sites inside the granular FHO were available for phosphate adsorption. The granular FHO shows excellent potential for use as an assist technology for advanced treatment of secondary effluents. 


\section{ACKNOWLEDGEMENTS}

This work was supported by Funds for the Creative Research Groups of China (No. 51,221,892) and the National Basic Research Program of China (2011CB933700).

\section{REFERENCES}

Aryal, M. \& Liakopoulou-Kyriakides, M. 20II Equilibrium, kinetics and thermodynamic studies on phosphate biosorption from aqueous solutions by Fe(III)-treated Staphylococus xylosus biomass: Common ion effect. Colloids and Surfaces aPhysicochemical and Engineering Aspects 387 (1-3), 43-49.

Blaney, L. M., Cinar, S. \& SenGupta, A. K. 2007 Hybrid anion exchanger for trace phosphate removal from water and wastewater. Water Research 41 (7), 1603-1613.

Boyer, T. H., Persaud, A., Banerjee, P. \& Palomino, P. 20II Comparison of low-cost and engineered materials for phosphorus removal from organic-rich surface water. Water Research 45 (16), 4803-4814.

Chao, T. T. \& Zhou, L. I983 Extraction techniques for selective dissolution of amorphous iron oxides from soils and sediments. Soil Sci. Soc. Am. J. 47 (2), 225-232.

Chen, L., Wang, T. J., Wu, H. X., Jin, Y., Zhang, Y. \& Dou, X. M. 20 II Optimization of a Fe-Al-Ce nano-adsorbent granulation process that used spray coating in a fluidized bed for fluoride removal from drinking water. Powder Technology 206 (3), 291-296.

Chitrakar, R., Tezuka, S., Sonoda, A., Sakane, K., Ooi, K. \& Hirotsu, T. 2006 Phosphate adsorption on synthetic goethite and akaganeite. Journal of Colloid and Interface Science 298 (2), 602-608.

Clauson-Kaas, J., Poulsen, T. S., Neergaard-Jacobsen, B., Guildal, T. \& Thirsing, C. 2004 Economic and environmental optimization of phosphorus removal. Water Science and Technology 50 (7), 243-248.

Correll, D. L. 1998 The role of phosphorus in the eutrophication of receiving waters: a review. J. Environ. Qual. 27 (2), 261-266.

Dou, X., Mohan, D. \& Pittman, Jr, C. U. 2013 Arsenate adsorption on three types of granular schwertmannite. Water Research 47 (9), 2938-2948.

Lai, C. H., Lo, S. L. \& Chiang, H. L. 2000 Adsorption/desorption properties of copper ions on the surface of iron-coated sand using BET and EDAX analyses. Chemosphere 41 (8), 1249-1255.

Mezenner, N. Y. \& Bensmaili, A. 2009 Kinetics and thermodynamic study of phosphate adsorption on iron hydroxide-eggshell waste. Chemical Engineering Journal 147 (2-3), 87-96.

Morse, G. K., Brett, S. W., Guy, J. A. \& Lester, J. N. I998 Review: Phosphorus removal and recovery technologies. Science of the Total Environment 212 (1), 69-81.
Pan, B. J., Wu, J., Pan, B. C., Lv, L., Zhang, W. M., Xiao, L. L., Wang, X. S., Tao, X. C. \& Zheng, S. R. 2009 Development of polymer-based nanosized hydrated ferric oxides (HFOs) for enhanced phosphate removal from waste effluents. Water Research 43 (17), 4421-4429.

Peleka, E. N. \& Deliyanni, E. A. 2009 Adsorptive removal of phosphates from aqueous solutions. Desalination 245 (1-3), 357-371.

Plant, L. J. \& House, W. A. 2002 Precipitation of calcite in the presence of inorganic phosphate. Colloids and Surfaces A: Physicochemical and Engineering Aspects 203 (1-3), 143-153.

Salman, A. D., Hounslow, M. J. \& Seville, J. P. K. 2007 Handbook of Powder Technology Volume 11 Granulation. Elsevier Science, Amsterdam, The Netherlands.

Schwertmann, U. \& Cornell, R. M. 2000 Iron oxides in the laboratory: preparation and characterization, 2 nd edn. Wiley-VCH, New York, USA.

Tian, S. L., Jiang, P. X., Ning, P. \& Su, Y. H. 2009 Enhanced adsorption removal of phosphate from water by mixed lanthanum/aluminum pillared montmorillonite. Chemical Engineering Journal 151 (1-3), 141-148.

Walker, G. M. 2007 Chapter 4 Drum Granulation Processes. In: Handbook of Powder Technology A.D (M. J. H. Salman \& J. P. K. Seville, eds). Elsevier Science B.V., The Netherlands, pp. 219-254.

Wei, X. C., Viadero, Jr, R. C. \& Bhojappa, S. 2008 Phosphorus removal by acid mine drainage sludge from secondary effluents of municipal wastewater treatment plants. Water Research 42 (13), 3275-3284.

Yue, Q., Zhao, Y., Li, Q., Li, W., Gao, B., Han, S., Qi, Y. \& Yu, H. 20I0 Research on the characteristics of red mud granular adsorbents (RMGA) for phosphate removal. Journal of Hazardous Materials 176 (1-3), 741-748.

Zeng, L., Li, X. M. \& Liu, J. D. 2004 Adsorptive removal of phosphate from aqueous solutions using iron oxide tailings. Water Research 38 (5), 1318-1326.

Zhang, Y., Yang, M., Dou, X. M., He, H. \& Wang, D. S. 2005 Arsenate adsorption on an Fe-Ce bimetal oxide adsorbent: Role of surface properties. Environmental Science \& Technology 39 (18), 7246-7253.

Zhang, Y., Dou, X. M., Zhao, B., Yang, M., Takayama, T. \& Kato, S. 2oro Removal of arsenic by a granular Fe-Ce oxide adsorbent: Fabrication conditions and performance. Chemical Engineering Journal 162 (1), 164-170.

Zhao, B., Zhang, Y., Dou, X. M., Wu, X. M. \& Yang, M. 2012 Granulation of $\mathrm{Fe}-\mathrm{Al}-\mathrm{Ce}$ trimetal hydroxide as a fluoride adsorbent using the extrusion method. Chemical Engineering Journal 185-186, 211-218.

Zhao, D. \& Sengupta, A. K. 1998 Ultimate removal of phosphate from wastewater using a new class of polymeric ion exchangers. Water Research 32 (5), 1613-1625. 